haematoma formation and no long-term sequelae.

We wish to make two points. Firstly, the technique of insertion of the cannula is very important in avoiding trauma to the artery. We feel the Grandjean cannula (which uses advance. On the great majority of occasions the puncture is "first time" and through the anterior wall of the artery only. Secondly, the continuous flush technique removes problems of thrombosis at the catheter tip. Since using the Grandjean catheter we failed only once to insert the cannula at the first attempt. We have had no significant haematoma formation at insertion or following removal. We do make a special point of formally examining the artery after insertion, at 12 hours, on removal at 24 hours, and at outpatient follow-up one month later.

We have had no instances of arterial thrombosis, or pulse diminution, or splinter haemorrhages and, despite careful observation, no patients have developed forearm claudication after microcannulation, though, like others, we have certainly seen this after routine cardiac catheterization. We have ourselves had repeated arterial cannulation by this method. Obviously no invasive procedure is entirely foolproof but we feel arterial microcannulation by this method is a safe procedure.-We are, etc.,

W. A. Littler P. SLEIGH

Radcliffe Infirmary,

Oxford

1 Hughes, U. G., and Prys-Roberts, C., Anaesthesia, 1971, 26, 511 .

2 Gribbin, B., Pickering, T. G., Sleight, P., and

\section{Ultrasonic Fetal Cephalometry}

SIR,-The development of this technique is as exciting for paediatricians as for the obstetricians who have been responsible for it. For the first time one of the parameters of growth in the fetus has become available. We now have the satisfying prospect of being able to follow continuously the growth of an individual through both prenatal and postnatal phases.

In order to see how estimates of fetal head size as obtained by ultrasonic cephalometry ${ }^{1}$ of head circumference after birth ${ }^{2}$ I have taken data from the curve for biparietal diameter by ultrasound obtained by Campbell and Newman, ${ }^{1}$ and multiplied this by an arbitrary factor 3.5 - that is, a factor somewhat higher than $\pi$-to allow for the elliptical shape of the head.

The satisfactory agreement of the last two diameter is multiplied by 3.5 a figure for head circumference as measured after birth should be obtained.

In this Table the data referred to are those published by S. Campbell. ${ }^{3}$ Dr. P. a semirigid steel stilette) is a very significant agree with those obtained by measurement columns implies that if fetal biparietal
Flamme (12 August, p. 384) provides data for biparietal diameter by ultra-sound which are consistently about $7 \%$ below those of Campbell, presumably owing to differences in technique. To convert Flamme's figures into head circumferences a multiplying factor of about 3.7 would be appropriate.-I am, etc.,

Addenbrooke's Hospital,

Douglas Gairdner Cambridge

Campbell, S., and Newman, G. B., fournal of Obstetrics and Gynaecology of the British Com Gairdner Dond

in Childhood, 1971, 46, 783 ., Archives of Disease
Camphell, S. Fournal of Obstetrics and Gynae cology of the British Commonwealth, 1968, 75 .
568 .

SIR,-I was interested to read the article by Dr. P. Flamme (12 August, p. 384) reporting the largest series of biparietal diameter measurements so far published and relating these to the number of completed weeks since the onset of the last menstrual period.

Unfortunately, measurements quoted in previous series ${ }^{2}$ differ by an amount which may result in a difference of up to four weeks in the gestational age estimated from the biparietal diameter. It appears that different types of ultrasonic apparatus give different values for the fetal biparietal diameter. Therefore before the results obtained by Dr. Flamme can be applied by other workers it is necessary to know what type of apparatus was used; the method used to determine the required angulations of the probe $;^{3}$ the criteria used to judge that an A scan was suitable for measurement; ${ }^{4}$ what type of calipers were used; how the apparatus was callibrated; and, most important of all, what speed of ultrasound was assumed. -I am, etc.

\section{City Hospital,}

P. Davies

1 Campbell, S.. and Newman, G. B., fournal of Obstetrics and Gynaecology of the British Com mon realth, 1971, 78, 513

Levi, S., Gynécologie et Obstétrique, 1970, 69,

Campbell, S., Fournal of Obstetrics and Gynae-
cology of the British Commonwealth, 1968, 75, 568 . Hellman, L. M., Kobayashi M., Fillisti. L., and and Gynecology, 1967, 99, 662 . Whittingham, T. A., British fournal of Radiology,
$1971,44,481$.

\section{Congenital Hepatic Fibrosis}

SIR,-Congenital hepatic fibrosis is a rare disease but one which poses a difficult therapeutic problem. It usually presents in early childhood with bleeding from oesophageal varices of a severity which demands surgery. The most effective operation is portacaval anastomosis. But these children have well preserved hepatic function and a long life expectation if bleeding can be controlled, and the possible effect of shunt operations on mental development during childhood has to be weighed against the greater risk of recurrent haemorrhage if a less effective operation is employed in order to avoid diverting portal blood from the liver. The choice would be facilitated if there were more information on the long-term prognosis of children treated by various operations, or without surgery, and if their intellectual performance as adults were known.

No one centre has enough patients with this disease to provide the necessary data. We are therefore undertaking, as a student research project, a follow-up of all the patients with congenital hepatic fibrosis we can find in this country. So far, through the courtesy of many physicians, surgeons, and paediatricians, we have contacted 20 patients but we suspect that there are many more whom we have not yet traced. We would therefore welcome information from any doctors who know of patients with congenital hepatic fibrosis. Where possible we would like to interview the patients, and we are willing to travel anywhere in the United Kingdom to visit them in their own homes, if necessary, by arrangement with their local doctors.

We would also be grateful for details of patients who cannot be contacted, who live outside the United Kingdom, or who have died to supplement our knowledge of longterm prognosis.-We are, etc.,

\section{Stella Oronkwo} GrRald Choa Medical Students

University of Newcastle upon Tyne,

Department of Medicine,

Newcastle upon Tyne NE1 4LP

\section{Toxicity of Podophyllum}

SIR,-It is right that attention should be drawn to the toxicity of podophyllum (12 August, p. 391) but wrong for the authors of the article on its toxic effect in pregnancy to condemn it out of hand in this context.

Apart from the serious consequences referred to, podophyllum can cause extremely unpleasant soreness to surrounding healthy tissue when the paint is applied to warts. The risk of this can be minimized by protecting the surrounding healthy skin with petroleum jelly before applying the paint and the danger of toxic absorption avoided by using minimal quantities on the one hand and instructing the patient to wash the paint off after six to eight hours on the other.

Using an orange stick and cotton wool swab it is possible to paint an area the size of one's fist with less than $2 \mathrm{ml}$ of paint. Large areas should be dealt with piecemeal and with less than this quantity, preferably no more often than once a week. No patient should be allowed the doubtful privilege of self application. This is a doctor's function.

Podophyllum resin in solution with alcohol or compound benzoin tincture is an extremely useful item in the armamentarium of gynaecologists and venereologists, but though dispensed with largesse it must not be so applied.-I am, etc.,

ARTHUR S. WIGFIELD

\begin{tabular}{c|c|c|c}
\hline Gestation (weeks) & $\begin{array}{c}\text { Biparietal Diameter by } \\
\text { Ultrasound }(\mathrm{cm})\end{array}$ & $\begin{array}{c}\text { Biparietal Diameter } \\
\times 3.5(\mathrm{~cm})\end{array}$ & $\begin{array}{c}\text { Observed Head Circum- } \\
\text { ference }(\mathrm{cm})\end{array}$ \\
\hline 28 & 7.5 & 26.3 & 26 \\
30 & 8.1 & 38.3 & 27.4 \\
32 & 8.6 & 31.0 & 29.9 \\
34 & 9.0 & 33.0 & 31.7 \\
36 & 9.4 & 34.0 & 33.2 \\
38 & 9.7 & 34.6 & 34.4 \\
40 & 9.9 & 34.6 \\
\hline
\end{tabular}

SIR,-In the interesting case described by Dr. M. J. Chamberlain and others (12 August, p. 391) the delayed recovery from anaesthesia followed by a mixed sensory and 